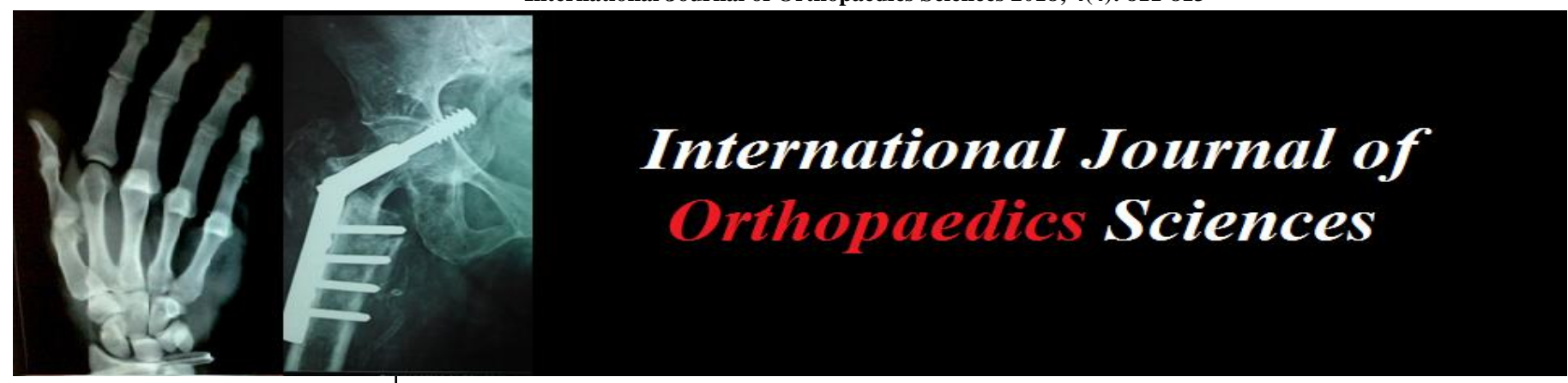

ISSN: $2395-1958$

IJOS 2018; 4(4): 811-813

(C) 2018 IJOS

www.orthopaper.com

Received: 04-08-2018

Accepted: 08-09-2018

Dr. A Mohamed Zubair

M.S.(Ortho) Registrar and Senior Assistant Professor, Department of Orthopaedics, Kanyakumari Medical College, Tamil Nadu, India

\section{Prospective study on functional outcome and role of hybrid external fixators in complex tibial plateau fractures}

\section{Dr. A Mohamed Zubair}

DOI: https://doi.org/10.22271/ortho.2018.v4.i4k.102

\section{Abstract}

Introduction: Tibial plateau fractures are common due to high energy injuries. The principles of treatment include respect for the soft tissues, restoring the congruity of the articular surface and reduction of the anatomic alignment of the lower limb to enable early movement of the knee joint. There are various surgical fixation methods that can achieve these principles of treatment.

Aim: To study the functional outcome and role of hybrid external fixators in complex tibial plateau fractures.

Methods: 50 Patients with Schatzker type V fractures and Schatzker type VI closed plateau fractures and Compound tibial fracture Grade I and IIIB were treated with both closed reduction and hybrid external fixation or with minimal open reduction and a hybrid system. Functional outcome were assessed with NEER's scoring system.

Results: Out of 50 cases 20 cases were type 5 and 30 cases were type 6 Schatzker and the average NEER scoring for them were 17.50 and 14.25 respectively. Most common complication is pin site infection, overcame by regular dressing and Knee stiffness. NEER's Rating score rating system for knee the $52 \%$ patients had excellent and $36 \%$ patients had good outcome.

Conclusion: The hybrid external fixator method we had applied is safe as regards of soft tissue healing and the limited number of complications associated directly to this method of application.

Keywords: hybrid external fixation, complex tibial fractures, NEER's score

\section{Introduction}

Tibial plateau fractures are peculiar in that they vary in complexity from relatively straightforward, low energy injuries to comminuted, high energy fractures with bad soft tissue status ${ }^{[1]}$. Schatzker, in 1979, introduced his classification system, which differentiates tibial plateau fractures in order or increasing complexity ${ }^{[2]}$. Thus, Schatzker V and VI represent a subset of fractures which are caused by a high energy mechanism, primarily axial loading with added angular force ${ }^{[3]}$. Complex tibial plateau fractures are usually high energy injuries presenting with significant articular and soft tissue damage in a major weight bearing joint. The restoration of the articular surface, joint stability, and axis is technically demanding. The soft tissue damage associated with the injury severity, only adds to the challenge of optimizing outcomes for these injuries ${ }^{[4]}$. Open injuries are also not uncommon, and can make even a relatively simple split fracture inappropriate for internal fixation ${ }^{[5]}$. The treatment of complex proximal tibial fractures is challenging, and till date, there is no clear consensus as to the ideal method of treatment. Data suggesting that minimally invasive or closed reduction and ring or hybrid external fixation is a safer equivalent to open reduction and internal fixation of Schatzker Type V and VI fractures have accumulated in the past decade ${ }^{[6]}$.

\section{Aim}

To study the functional outcome and role of hybrid external fixators in complex tibial plateau fractures.

Materials and Methods

This is a prospective study was conducted in Department of Orthopedics. Patients with
Dr. A Mohamed Zubair M.S.(Ortho) Registrar and Senior Assistant Professor, Department of Orthopaedics, Kanyakumari Medical College, Tamil Nadu, India 
Schatzker type V fractures and Schatzker type VI closed plateau fractures and Compound tibial fracture Grade I and IIIB were included.

\section{Exclusion criteria}

1. Closed Tibial plateau fractures (Schatzker type 1 to 4 )

2. Compound tibial plateau grade IIIc fractures

3. Associated fractures like floating knee, pilon fractures.

All fractures were treated with both closed reduction and hybrid external fixation or with minimal open reduction and a hybrid system

After surgery the patient symptom was subsided, patient walked with walker with touch toe. After 2 weeks the patient was started on partial weight bearing walking with walker and six weeks full weight bearing with walker support. After 6 weeks the fracture was united radiographically. Fixator was removed and PTB cast applied with patient allowed to full weight bearing walking. After 2 weeks the PTB cast was removed and start to walk with walker and gradually discarded the walker. Functional outcome were accessed using NEER's rating score.

\section{Results}

In this study 50 patients were included, 36 male and 14 female. Male predominance was observed. Mean age of the patients is $42.14 \pm 12.46$ years. Road traffic accident predominates assault in mode of injury perhaps fall injury stood last. Among the high energy fractures of tibial condyle, type 6 showed more frequency. Type 5 almost equals the frequency.

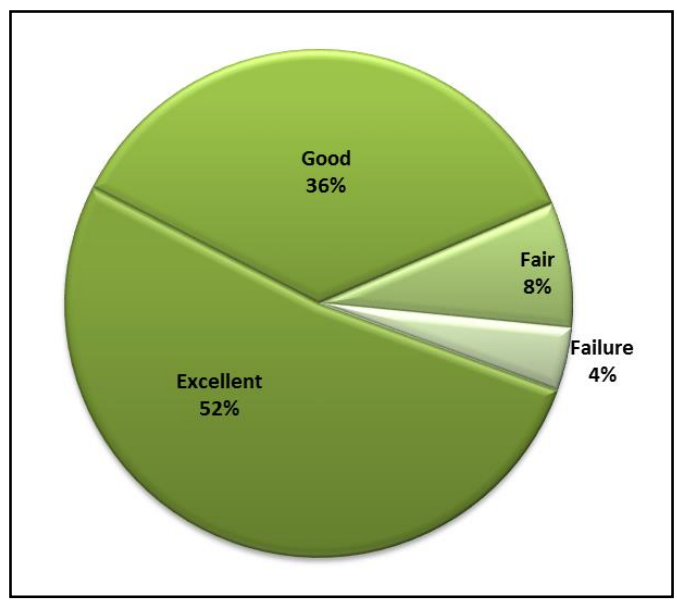

Fig 1: Distribution of NEERs Score

NEER's Rating score rating system for knee the $52 \%$ patients had excellent and $36 \%$ patients had good outcome. (Figure 1)

Table 1: NEER's Rating Score according to Schatzker's type

\begin{tabular}{|c|c|c|}
\hline $\begin{array}{c}\text { Schatzker's } \\
\text { type }\end{array}$ & Number of cases & $\begin{array}{c}\text { Average NEER's } \\
\text { rating score }\end{array}$ \\
\hline Type 5 & 20 & 17.5 \\
\hline Type 6 & 30 & 14.25 \\
\hline
\end{tabular}

Out of 50 cases 20 cases were type 5 and 30 cases were type 6 Schatzker and the average NEER scoring for them were 17.50 and 14.25 respectively. (Table 1 )

Table 2: Results based on type of fracture (closed /open)

\begin{tabular}{|c|c|c|}
\hline Fracture & Number of cases & Average Neer's rating score \\
\hline Closed fracture & 18 & 17.58 \\
\hline Compound & 32 & 14.68 \\
\hline
\end{tabular}

Out of 50 cases our study had 18 cases of closed fracture and 32 cases of compound fracture which were treated by hybrid fixator showed average NEER score of 17.58 and 14.68 respectively. (Table 2).

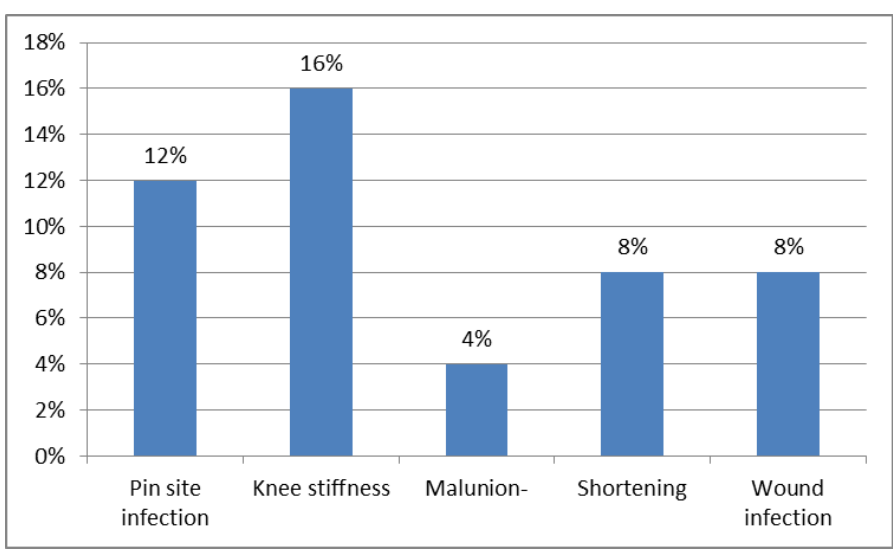

Fig 2: Complications

Most common complication is pin site infection, overcame by regular dressing. Knee stiffness found in $20 \%$ of patients, managed by physiotherapy. (Figure 2)

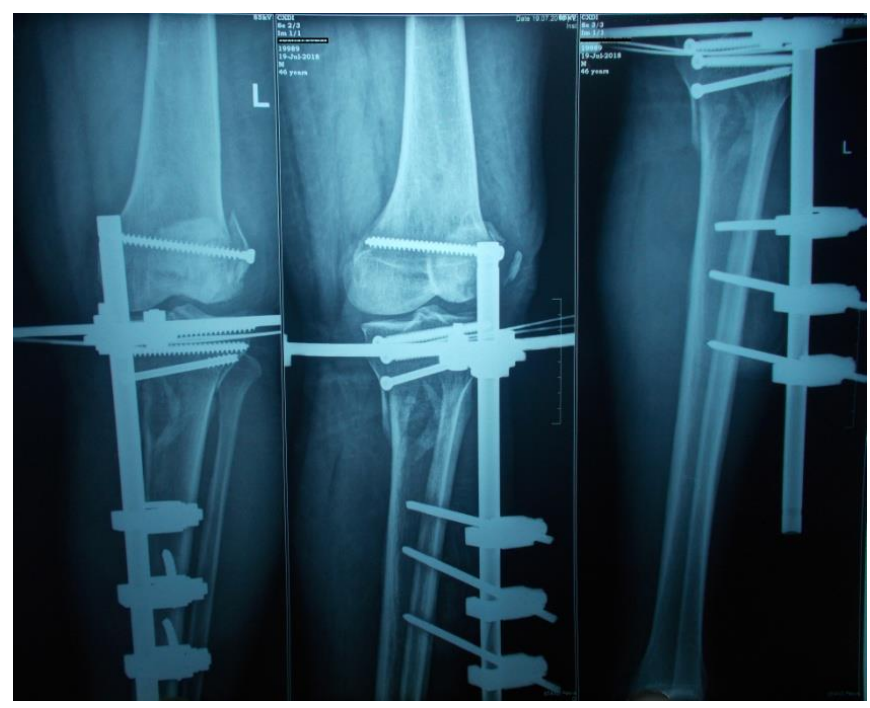

Fig 3: Radiograph after the application of hybrid external fixator in Left tibia with intercondylar extension with comminuted patellar; with lateral condyle communited fracture

\section{Discussion}

The fact is well established that a healthy soft tissue envelope is indispensable to successful healing of a fracture. Tibial plateau fractures, especially S-V and SVI are high energy fractures that are frequently associated with a compromised soft tissue ${ }^{[7]}$. The average time for fracture healing was 8 weeks (ranging from 6 weeks to 10 weeks). Fracture pattern, type of fracture (closed/open), and presence of infection significantly affected the fracture healing. Anatomical reduction and relatively stable fixation had early rehabilitation and reduced complications ${ }^{[8,9]}$ Previous studies reported the importance of stability of the knee after treatment of tibia plateau fractures as one of the most important predictors for future knee function ${ }^{[10]}$.

In the last 2 decades, the evolution of devices and techniques of external fixation has led many surgeons to apply the principles of biologic osteosynthesis and minimally invasive surgery for the treatment of comminuted tibial plateau fractures $[11,12]$ The development of circular and hybrid 
frames, the capability of axial, lateral compression and dynamization, the development of olive wires have offered new possibilities to the external fixators for the treatment of complex fractures ${ }^{[13]}$ Mahadena et al, comparing external to internal fixation, concluded that hybrid external fixation possesses theoretical advantages in terms of the soft tissues protection; however the benefit over internal fixation is modest as far as accuracy of reduction is concerned ${ }^{[14]}$.

Chin et al presented $38.9 \%$ good / excellent, and $61.1 \%$ fair / poor results in his type V and VI fractures series ${ }^{[15]}$ Catagni et $a l$, in their series of high-energy Schatzker V and VI tibial plateau fractures treated with circular external fixator, reported excellent and good results in 30 (50.85\%) and 27 $(45.766 \%)$ patients respectively ${ }^{[16]}$.

\section{Conclusion}

High energy tibial plateau fractures pose management challenges because of the complexity of the bony and soft tissue injury. Internal fixation can lead to bad outcomes if done through unfavourable skin in S-V and S-VI and grade 3 open fractures. The hybrid external fixator is a very good treatment modality to tackle such fractures. It allows good reduction, adequate stabilization and early knee mobilization which are the goals of any operative fracture management modality.

\section{References}

1. Oestern HJ, Tscherne H. Pathophysiology and Classification of Soft Tissue Injuries Associated with Fractures. In Fractures with Soft Tissue Injuries, Springer-Verlag. Edited by: Tscherne H, Gotzen L. Berlin; 1984, 1-9.

2. Schatzker J, McBroom R, Bruce D. The tibial plateau fracture: the Toronto experience 1968-1975. Clin Orthop. 1979; 138:94-104.

3. Coval DJ, Fowble CD, Foster TE, Whitelaw GP. Bicondylar tibial plateau fractures: Principles of treatment. Contemp Orthop. 1994; 28:115-22.

4. Papagelopoulos PJ, Partsinevelos AA, Themistocleous GS, Mavrogenis AF, Korres DS, Soucacos PN. Complications after tibia plateau fracture surgery. Injury. 2006; 37:475-84.

5. Swiontkowski MF, Bucholz RWL. Knee and Leg Trauma: Bone Trauma. In: Orthopaedic Knowledge Update American Academy of Orthopaedic Surgeons. Edited by: Frymoyer JW. Rosemont, 1993, 579-92.

6. Piper KJ, Won HY, Ellis AM. Hybrid external fixation in complex tibial plateau and plafond fractures: An Australian audit of outcomes. Injury. 2005; 36:178-84.

7. Rommens PM, Broos PL. The significance of soft tissue trauma for fracture healing. A prospective study on 70 tibial shaft fractures following primary treatment with the Monofixateur. Unfallchirurg. 1992; 95(3):133-41.

8. Madhor A Karunakar, Micheal J bose. Rockwood and Greens "Fracture in adults". 5th edition, chapter 2001, 231-245.

9. Mark Farrar, Lang yans, Micheal salen. The Sheffield Hybrid Fixator- a clinical and biomechanical review. INJURY. 2001; 32:8-13.

10. Marsh JL, Buckwalter J, Gelberman R, et al. Articular fractures: does an anatomic reduction really change the result? J Bone Joint Surg Am. 2002; 84A:1259-1271.

11. Stamer DT, Schenk R, Staggers B, Aurori K, Aurori B, Behrens FF. Bicondylar tibial plateau fractures treated with a hybrid ring external fixator: a preliminary study. J
Orthop Trauma. 1994; 8:455-461.

12. Young MJ, Barrack RL. Complications of internal fixation of tibial plateau fractures. Orthop Rev. 1994; 23:149-54

13. Keoch P, Kelly C, Cashman WF, McGuinness AJ, O Rourke SK. Percutaneous screw fixation of tibial plateau fractures. Injury. 1992; 23:387-389.

14. Mahadeva D, Costa ML, Gafrey A. Open reduction and internal fixation versus hybrid fixation for bicondylar/severe tibial plateau fractures: a systematic review of the literature. Arch Orthop Trauma Surg. 2008; 128:1169-75. doi: 10.1007/s00402-007-0520-7.

15. Chin TYP, Bardana D, Bailey M, Williamson OD, Miller $\mathrm{R}$, Edwards ER, et al. Functional outcome of tibial plateau fractures treated with the fine-wire fixator. Injury. 2005; 36:1467-1475. doi: 10.1016/j.injury.2005.05.008.

16. Catagni MA, Ottaviani G, Maggioni M. Treatment strategies for complex fractures of the tibial plateau with external circular fixation and limited internal fixation. $\mathbf{J}$ Trauma. 2007; 63:1043-1053. doi: 10.1097/TA.0b013e3181238d88. 